\title{
Osmotic characteristics and fertility of murine spermatozoa collected in different solutions
}

\author{
Wei Si, Hongsheng Men, James D Benson and John K Critser \\ Research Animal Diagnostic Laboratory, College of Veterinary Medicine, Comparative Medicine Center, University of \\ Missouri, 4011 Discovery Drive, Columbia, Missouri 65201, USA \\ Correspondence should be addressed to J K Critser; Email: critserj@missouri.edu
}

W Si and H Men contributed equally to this work

W Si is now at Department of Reproductive Medicine, Medical College of Georgia, Institute of Molecular Medicine and Genetics, Augusta, Georgia 30912, USA. Email: wsi@mail.mcg.edu

\begin{abstract}
Osmotic stress is an important factor that can result in cell damage during cryopreservation. Before ejaculation or collection for cryopreservation, murine spermatozoa are stored in epididymal fluid, a physiologically hyperosmotic environment ( $\sim 415 \mathrm{mmol} / \mathrm{kg})$. The objectives of this study were to determine the osmotic tolerance limits of sperm motion parameters of ICR and C57BL/6 mouse spermatozoa collected in isosmotic $(290 \mathrm{mmol} / \mathrm{kg}$ ) and hyperosmotic $(415 \mathrm{mmol} / \mathrm{kg})$ media, and the effect of the osmolality of sperm collection media on sperm fertility after cryopreservation. Our results indicate that murine spermatozoa collected in media with different osmolalities (290 and $415 \mathrm{mmol} / \mathrm{kg}$ Dulbecco's phosphate buffered saline (DPBS)) appeared to have different osmotic tolerances for the maintenance of sperm motility and other motion parameters in both mouse strains. The hypo- and hyperosmotic treatments decreased motility and affected other motion parameters of spermatozoa collected in $290 \mathrm{mmol} / \mathrm{kg}$ DPBS. The extent of the change of motion parameters after treatments corresponded with the levels of osmotic stress. However, for spermatozoa collected in $415 \mathrm{mmol} / \mathrm{kg}$ DPBS, exposure to $290 \mathrm{mmol} / \mathrm{kg}$ DPBS tended to increase sperm motility and the quality of their motion parameters. The osmolality of sperm collection medium can affect murine sperm fertility. Spermatozoa collected in $415 \mathrm{mmol} / \mathrm{kg}$ medium showed higher fertility compared with spermatozoa collected in $290 \mathrm{mmol} / \mathrm{kg}$ as assessed by IVF. Results characterizing murine sperm osmotic tolerance collected in media with different osmolalities from different strains and the effect of collection media osmolality on sperm fertility after cryopreservation will be useful in designing cryopreservation protocols.

Reproduction (2009) 137 215-223
\end{abstract}

\section{Introduction}

Cryopreservation of murine spermatozoa has been of great interest in the biomedical community due to an exponential increase in genetically modified mouse models of human disease (Critser \& Mobraaten 2000). Banking murine spermatozoa of all existing strains by efficient sperm cryopreservation protocols would significantly relieve the burden and the cost of conventional maintenance of these strains/lines as live animals (Sharp \& Mobraaten 1997, Knight \& Abbott 2002). Currently, the protocol developed by Nakagata $(2000 a, 2000 b)$ is widely used as a method for the banking of murine spermatozoa of various strains at laboratories around the world. However, there has been no significant improvement since the development of that protocol (Critser \& Mobraaten 2000) until recently when Stacy et al. (2006) improved the cryosurvival of mouse spermatozoa by optimizing the cooling rate of Nakagata's mouse sperm protocol and Bath (2003) achieved
$38-88 \%$ fertilization rate by removing non-motile spermatozoa and cell debris from thawed sperm suspension of $\mathrm{C} 57 \mathrm{BL} / 6 \mathrm{~J}$ mouse.

The cryobiological behavior of murine spermatozoa appears to be quite different from other types of cells and even spermatozoa from other species (Critser \& Mobraaten 2000). Previous work has demonstrated that a permeating cryoprotectant such as glycerol may not be needed and may even be detrimental to murine spermatozoa during cryopreservation (Katkov et al. 1998); the most successful protocol for murine sperm cryopreservation requires media consisting of only nonpermeating cryoprotectants (for example, raffinose and skimmed milk; Nakagata 2000a, 2000b). Because of the uniqueness of murine spermatozoa in response to cryopreservation, it is necessary to gain an in-depth understanding of their fundamental cryobiological properties in order to improve current murine sperm cryopreservation protocols and to develop an optimized 
protocol that could be consistently applied to the cryopreservation of murine spermatozoa from inbred strains as well as genetically modified lines.

During equilibrium cryopreservation, cells are dehydrated to a certain extent to prevent the formation of intracellular ice, a lethal condition that can result in the loss of viability of the cells. Usually chemical cryoprotective agents (CPAs) are used to achieve this purpose. Subsequently, the CPA(s) must be removed from the cells and their media after warming. During the processes of CPA addition and removal, cells experience osmotically driven volume changes. It has been demonstrated that murine spermatozoa are very sensitive to osmotic stress (Willoughby et al. 1996, Agca et al. 2002, Walters et al. 2005). Because of this, murine spermatozoa have a very limited ability to swell or shrink in response to osmotically driven volume excursions. In order to maintain $\geq 90 \%$ motility of murine spermatozoa from the B6C3F1 strain, volume excursions of the spermatozoa must be kept between 90 and $103 \%$ of isotonic volume (Willoughby et al. 1996).

For in vitro manipulation of murine spermatozoa, such as IVF, intracytoplasmic sperm injection as well as sperm biology studies, the media used for sperm collection have typically had an osmolality of $\sim 290 \mathrm{mmol} / \mathrm{kg}$ (Nagy 2003). However, recent studies examining the osmolality of cauda epididymal fluid found that murine spermatozoa are actually stored in a hyperosmotic milieu in cauda epididymides ranging from 375 to $500 \mathrm{mmol} / \mathrm{kg}$ (Yeung et al. 1999, Cooper \& Barfield 2006, Cooper et al. 2008). Even after ejaculation, spermatozoa are still at a slightly hyperosmotic condition in the female reproductive tract (uterine fluid is $330 \mathrm{mmol} / \mathrm{kg}$; Yeung et al. 2000). From this we can see that murine spermatozoa are maintained in hyperosmotic conditions during nearly their entire life.

The widely used murine sperm freezing media, either consisting of raffinose and PBS (Koshimoto \& Mazur 2002) or raffinose, skimmed milk, and water (Nakagata et al. 1997), have an osmolality of $418-480 \mathrm{mmol} / \mathrm{kg}-$ close to the osmolality of epididymal fluid (Yeung et al. 1999, 2006). However, previous studies defining the osmotic tolerance limits (OTLs) of mouse strains have used a sperm collection media with osmolality of 290 or $300 \mathrm{mmol} / \mathrm{kg}$ (Willoughby et al. 1996, Songsasen \& Leibo 1997, Agca et al. 2002, Walters et al. 2005). Because the osmolality of the cauda epididymides ranges from 375 to $500 \mathrm{mmol} / \mathrm{kg}$ (Yeung et al. 2006, Cooper et al. 2008), spermatozoa have been subjected to a hyposmotic challenge during collection, and under hyposmotic conditions, sperm regulatory volume decreases, and osmolyte loss occurs, which are related to sperm fertility (Yeung et al. 2006, Cooper et al. 2008). Because of the extreme sensitivity of murine spermatozoa to osmotically driven volume excursions, we were interested in looking at the OTLs of murine spermatozoa when collected at $415 \mathrm{mmol} / \mathrm{kg}$ and challenged with anisosmotic solutions using $415 \mathrm{mmol} / \mathrm{kg}$ as the nominal isosmotic point and the osmolalities of sperm collection medium on sperm fertility after cryopreservation. Furthermore, a previous study has found that volume regulation of spermatozoa after exposure to hypotonic conditions is related to the influx of calcium and the subsequent achievement of fertility (Rossato et al. 1996). In addition to motility, other sperm motion parameters are also important for the assessment of murine sperm quality and fertility (Toth et al. 1991). Therefore, the effects of anisosmotic treatments on other sperm motion parameters have been associated with sperm fertility were also investigated in this study.

The objective of the present study was to investigate the OTLs of murine spermatozoa from ICR and C57BL/6 strains collected in an isosmotic solution $(290 \mathrm{mmol} / \mathrm{kg})$ and a hyperosmotic solution with an osmolality similar to epididymal fluid $(415 \mathrm{mmol} / \mathrm{kg})$ and their fertilization capabilities after cryopreservation.

\section{Results}

\section{Experiment 1. The comparison of motion parameters of spermatozoa collected and assessed in 290 and $415 \mathrm{mmol} / \mathrm{kg}$ DPBS}

The motion parameters (motility, average path velocity (VAP), straight line velocity (VSL), curvilinear velocity $(\mathrm{VCL})$, lateral head displacement (ALH), and linearity (LIN)) of spermatozoa collected in 290 and $415 \mathrm{mmol} / \mathrm{kg}$ Dulbecco's phosphate buffered saline (DPBS) are shown in Fig. 1A-F. A significant difference was found for motility between the spermatozoa collected in 290 and $415 \mathrm{mmol} / \mathrm{kg}$ DPBS within each strain in both strains $(P<0.05)$. In ICR mice, the motility of spermatozoa collected in $290 \mathrm{mmol} / \mathrm{kg}$ DPBS was significantly lower than that of spermatozoa collected in $415 \mathrm{mmol} / \mathrm{kg}$ DPBS (64.6 vs $70.5 \%$ respectively; $P<0.05$ ). In C57BL/6 mice, however, the motility of spermatozoa in $290 \mathrm{mmol} / \mathrm{kg}$ DPBS was significantly higher than that of spermatozoa collected in $415 \mathrm{mmol} / \mathrm{kg}$ DPBS (73.3 vs $45.6 \%$ respectively; $P<0.05)$. In both strains, the values of VAP, VSL, VCL, and LIN of motile spermatozoa collected in $290 \mathrm{mmol} / \mathrm{kg}$ DPBS were found to be significantly higher than those of spermatozoa collected in $415 \mathrm{mmol} / \mathrm{kg}$ DPBS $(P<0.05)$. The value of $\mathrm{ALH}$ of motile spermatozoa collected in $290 \mathrm{mmol} / \mathrm{kg}$ DPBS was found to be significantly higher than that of spermatozoa collected in $415 \mathrm{mmol} / \mathrm{kg}$ DPBS only in the $\mathrm{C} 57 \mathrm{BL} / 6$ strain $(P<0.05)$.

\section{Experiment 2. The effect of anisosmotic treatments on sperm motion parameters (motility, VAP, VSL, VCL, $A L H$, and LIN)}

Significant main effects $(P<0.05)$ of osmolalities of sperm collection media (290 and $415 \mathrm{mmol} / \mathrm{kg}$ respectively) and genetic background were found on the 

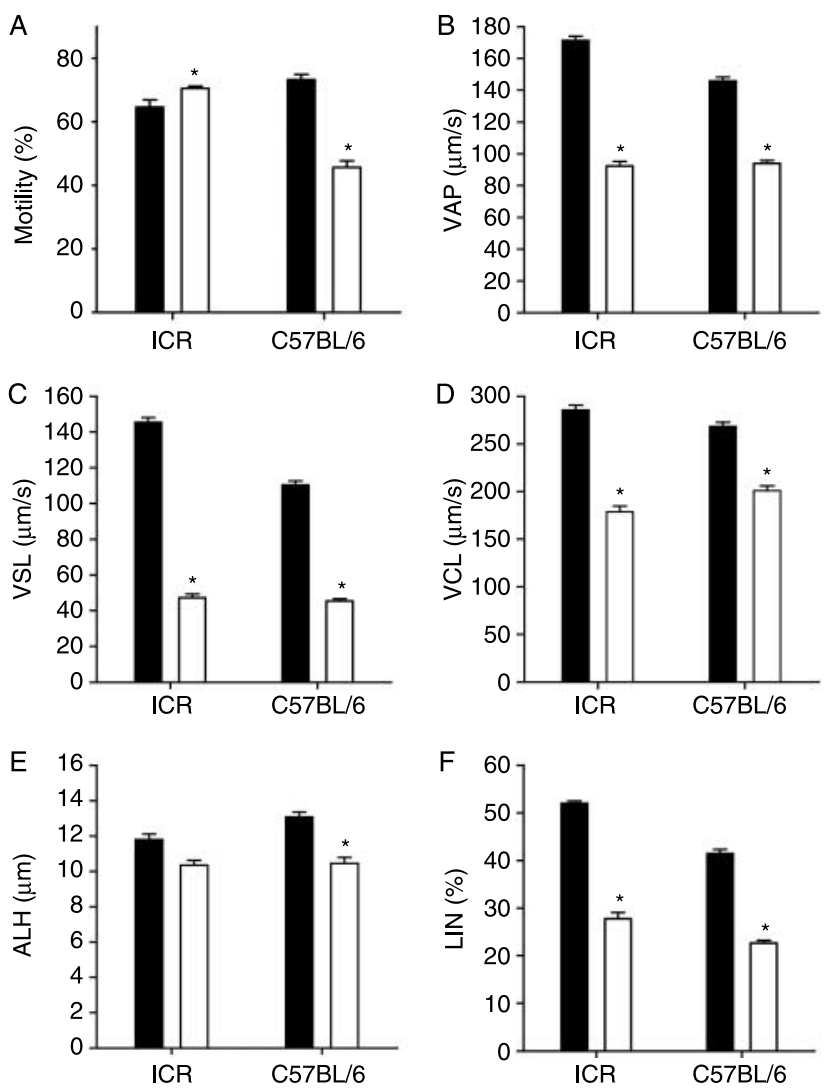

Figure 1 (A) Motility, (B) average path velocity (VAP), (C) straight line velocity (VSL), (D) curvilinear velocity $(\mathrm{VCL})$, (E) lateral head displacement (ALH), and (F) linearity (LIN) of ICR and C57BL/6 mice spermatozoa collected in 290 (solid bar) and 415 (open bar) mmol/kg DPBS. *Significantly different between 290 and $415 \mathrm{mmol} / \mathrm{kg}$ DPBS within same strain.

maintenance of sperm parameters after the anisosmotic treatments and upon return to the initial osmotic conditions.

The effects of the anisosmotic treatments on sperm motion parameters of the ICR and $\mathrm{C} 57 \mathrm{BL} / 6$ mice are shown in Figs 2 and 3 respectively. As shown in Fig. 2A, the motility of ICR murine spermatozoa collected either in $290 \mathrm{mmol} / \mathrm{kg}$ or 415 DPBS was decreased significantly after all of the anisosmotic treatments $(P<0.05)$. After a return to anisosmotic condition $(290 \mathrm{mmol} / \mathrm{kg})$, the motility of spermatozoa collected in $290 \mathrm{mmol} / \mathrm{kg}$ was not significantly increased $(P>0.05)$. However, for spermatozoa collected in $415 \mathrm{mmol} / \mathrm{kg}$ DPBS, the motility of spermatozoa treated with 150, 225, and $290 \mathrm{mmol} / \mathrm{kg}$ solutions was significantly decreased after being returned to initial osmolality $(415 \mathrm{mmol} / \mathrm{kg}$; $P<0.05)$. Only the motility of spermatozoa treated with $600 \mathrm{mmol} / \mathrm{kg}$ was significantly increased after being returned to $415 \mathrm{mmol} / \mathrm{kg}(P<0.05)$. As shown in Fig. $3 \mathrm{~A}$, the motility of $\mathrm{C} 57 \mathrm{BL} / 6$ mouse spermatozoa collected in $290 \mathrm{mmol} / \mathrm{kg}$ DPBS was significantly decreased after being exposed to anisosmotic solutions
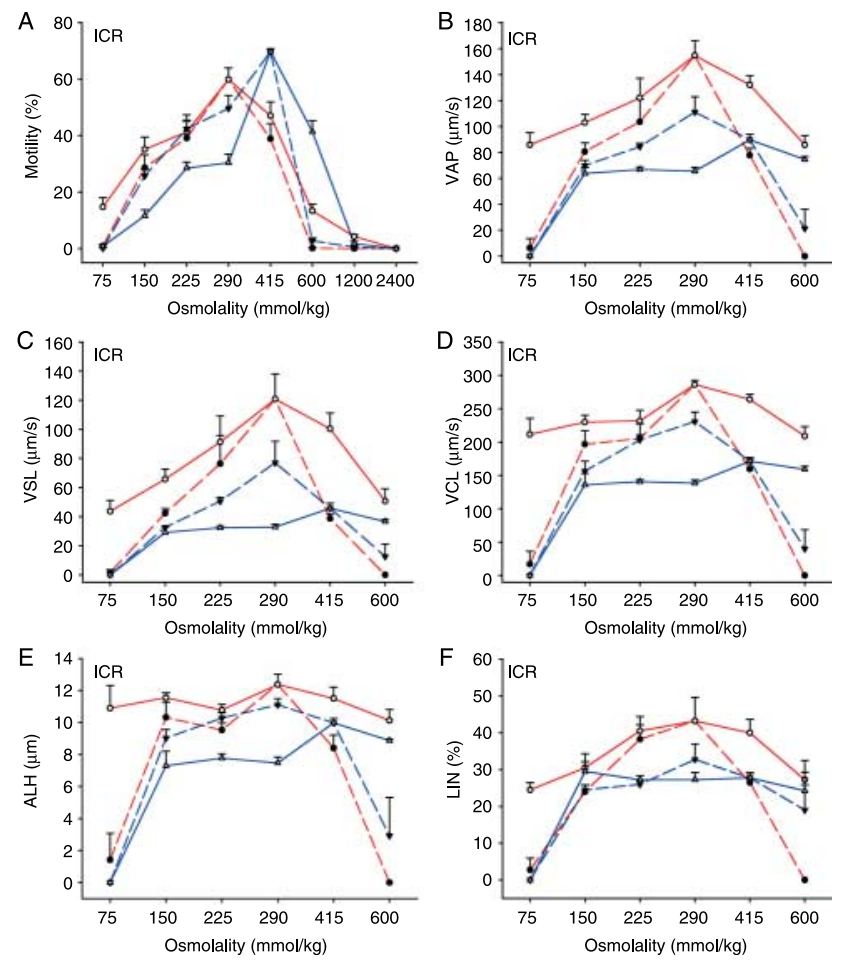

Figure 2 The motion parameters (A-F) of sperm from ICR mice collected in 290 (red lines) and $415 \mathrm{mmol} / \mathrm{kg}$ (blue lines) DPBS that were abruptly exposed to different osmotic conditions (dash lines) and abruptly returned to initial conditions (solid lines).

$(P<0.05)$. However, for the spermatozoa collected in $415 \mathrm{mmol} / \mathrm{kg}$ DPBS, the motility of spermatozoa exposed to 225 and $290 \mathrm{mmol} / \mathrm{kg}$ solutions was not decreased but was significantly increased when compared with spermatozoa kept in $415 \mathrm{mmol} / \mathrm{kg}$ DPBS $(P<0.05)$. After being returned to $415 \mathrm{mmol} / \mathrm{kg}$, the motility of spermatozoa treated with 150, 225, and $290 \mathrm{mmol} / \mathrm{kg}$ was significantly decreased to a level lower than those kept in $415 \mathrm{mmol} / \mathrm{kg}$ DPBS $(P<0.05)$.

The effects of the anisosmotic treatments on other parameters (VAP, VSL, VCL, ALH, and LIN) of motile spermatozoa collected in 290 and $415 \mathrm{mmol} / \mathrm{kg}$ DPBS are summarized in Figs 2B-F and 3B-F. Since the motility of spermatozoa collected in 290 or $415 \mathrm{mmol} / \mathrm{kg}$ DPBS and treated with 1200 and $2400 \mathrm{mmol} / \mathrm{kg}$ solutions were less than $5 \%$ in both strains (Figs $2 \mathrm{~A}$ and $3 \mathrm{~A}$ ), the spermatozoa treated with 1200 and $2400 \mathrm{mmol} / \mathrm{kg}$ were excluded from the following studies of the ability of motile spermatozoa maintaining VAP, VSL, VCL, ALH, and LIN during anisosmotic treatments.

In general, for spermatozoa collected in $290 \mathrm{mmol} / \mathrm{kg}$ DPBS, the responses of VAP, VSL, VCL, ALH, and LIN of motile spermatozoa to anisosmotic treatments were very similar between ICR and C57BL/6 mice. The exposure to anisosmotic solutions decreased the values of these motion parameters of motile spermatozoa and a return to initial osmolality recovered those motion 

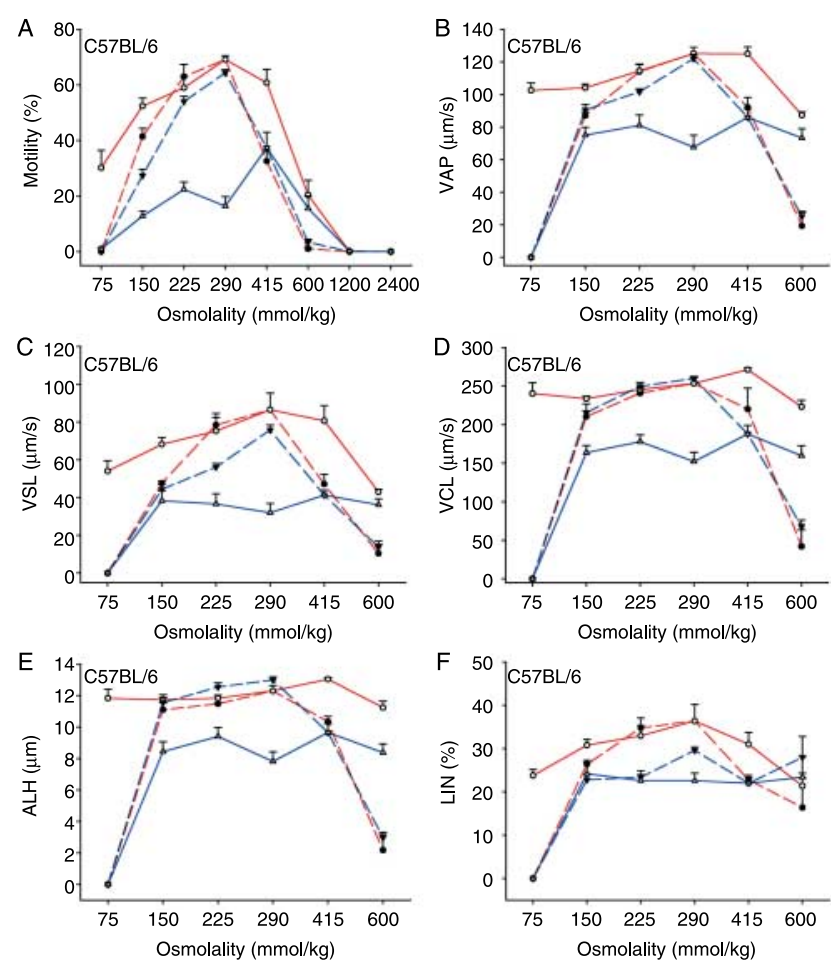

Figure 3 The motion parameters (A-F) of spermatozoa from C57BL/6 mice collected in 290 (red lines) and $415 \mathrm{mmol} / \mathrm{kg}$ (blue lines) DPBS that were abruptly exposed to different osmotic conditions (dash lines) and abruptly returned to initial conditions (solid lines).

parameters in some treatments (Figs $2 \mathrm{~B}-\mathrm{F}$ and $3 \mathrm{~B}-\mathrm{F}$ ). The extent of the decrease of motion parameters after treatments corresponded with the levels of osmotic stress, which is in accord with the response of sperm motility to anisosmotic treatments. The responses of VAP, VSL, VCL, ALH, and LIN of motile spermatozoa collected in $415 \mathrm{mmol} / \mathrm{kg}$ DPBS to anisosmotic treatments were also very similar between the two mouse strains. The exposure of spermatozoa to low osmotic solutions especially to $290 \mathrm{mmol} / \mathrm{kg}$ DPBS increased the VAP, VSL, VCL, ALH, and LIN values of motile spermatozoa when compared with the spermatozoa kept in $415 \mathrm{mmol} / \mathrm{kg}$ DPBS in both ICR and C57BL/6 strains. However, the increase in VAP, VSL, VCL, ALH, and LIN was only significant in C57BL/6 $(P<0.05)$. After being returned to initial osmotic conditions $(415 \mathrm{mmol} /$ $\mathrm{kg}$ ), the VAP, VSL, VCL, ALH, and LIN values of motile spermatozoa treated with $290 \mathrm{mmol} / \mathrm{kg}$ solutions in both strains were significantly reduced to a similar level or lower than the spermatozoa kept in $415 \mathrm{mmol} /$ $\mathrm{kg}$ DPBS (Figs 2B-F and 3B-F; $P<0.05$ ). The exposure of spermatozoa to hyperosmotic solution $(600 \mathrm{mmol} / \mathrm{kg})$ decreased the VAP, VSL, VCL, and ALH values of motile spermatozoa when compared with the spermatozoa kept in $415 \mathrm{mmol} / \mathrm{kg}$ DPBS in both ICR and C57BL/6 strains $(P<0.05)$. After being returned to initial osmotic conditions $(415 \mathrm{mmol} / \mathrm{kg})$, the VAP, VSL, VCL, and ALH values of motile spermatozoa treated with $600 \mathrm{mmol} / \mathrm{kg}$ solution in both strains were significantly increased $(P<0.05)$. However, the differences between LIN values of spermatozoa in hyperosmotic solution $(600 \mathrm{mmol} / \mathrm{kg})$ and after being returned to initial osmotic conditions $(415 \mathrm{mmol} / \mathrm{kg})$ were not significantly different in both strains $(P>0.05)$.

\section{Experiment 3. The effects of collection media osmolality on sperm cryopreservation and IVF}

As shown in Tables 1 and 2, the motility, VAP, VSL, VCL, $\mathrm{ALH}$, and LIN of spermatozoa collected either in 290 or $415 \mathrm{mmol} / \mathrm{kg}$ raffinose medium were significantly decreased after cryopreservation compared with fresh spermatozoa from both strains $(P<0.05)$. However, no significant difference in LIN values was observed between fresh spermatozoa and frozen-thawed spermatozoa from C57BL/6 that were collected either in 290 or $415 \mathrm{mmol} / \mathrm{kg}$ raffinose medium before cryopreservation $(P>0.05)$. Similar results were also obtained for spermatozoa from ICR $(P>0.05)$. In $\mathrm{C} 57 \mathrm{BL} / 6$ strain, the VAP of frozen-thawed spermatozoa that were collected in $415 \mathrm{mmol} / \mathrm{kg}$ medium before cryopreervation, was significantly higher than that of spermatozoa collected in $290 \mathrm{mmol} / \mathrm{kg}$ medium $(P<0.05)$. However, this difference was not observed in ICR mice $(P>0.05)$.

Cryopreserved spermatozoa from ICR mice were further used for IVF to assess the effect of the osmolalities of sperm collection media on sperm fertilizing ability. As shown in Table 3, the percentages of cleavage and blastocysts by frozen-thawed spermatozoa that were collected in $290 \mathrm{mmol} / \mathrm{kg}$ medium before cryopreservation were significantly lower than those by spermatozoa collected in $415 \mathrm{mmol} / \mathrm{kg}$ medium and fresh spermatozoa $(P<0.05)$.

Table 1 Motion parameters of fresh spermatozoa (non-frozen) and frozen-thawed spermatozoa from ICR mice that collected in 290 and $415 \mathrm{mmol} / \mathrm{kg}$ group media for cryopreservation.

\begin{tabular}{|c|c|c|c|c|c|c|}
\hline Collection medium & Motility (\%) & $\operatorname{VAP}(\mu \mathrm{m} / \mathrm{s})$ & $\mathbf{V S L}(\mu \mathrm{m} / \mathrm{s})$ & $\mathbf{V C L}(\mu \mathrm{m} / \mathrm{s})$ & $\operatorname{ALH}(\mu \mathrm{m})$ & LIN $(\%)$ \\
\hline Non-frozen group & $78 \pm 4^{\mathrm{a}}$ & $168 \pm 12^{a}$ & $120 \pm 13^{a}$ & $326 \pm 18^{a}$ & $16 \pm 1^{\mathrm{a}}$ & $36 \pm 3^{a}$ \\
\hline $290 \mathrm{mmol} / \mathrm{kg}$ group & $30 \pm 2^{b}$ & $117 \pm 8^{\mathrm{b}}$ & $89 \pm 8^{\mathrm{b}}$ & $224 \pm 10^{b}$ & $12 \pm 1^{b}$ & $38 \pm 2^{a}$ \\
\hline $415 \mathrm{mmol} / \mathrm{kg}$ group & $28 \pm 4^{b}$ & $118 \pm 7^{b}$ & $88 \pm 8^{b}$ & $233 \pm 6^{b}$ & $13 \pm 1^{b}$ & $36 \pm 2^{a}$ \\
\hline
\end{tabular}

Different superscripts in a column indicate significant difference, $P<0.05$. *Sperm motion parameters were measured in $290 \mathrm{mmol} / \mathrm{kg}$ DPBS containing $2 \mathrm{mg} / \mathrm{ml}$ BSA after thawing. 
Table 2 Motion parameters of fresh spermatozoa (non-frozen) and frozen-thawed spermatozoa from C57BL/6 mice that collected in 290 and $415 \mathrm{mmol} / \mathrm{kg}$ group media for cryopreservation.

\begin{tabular}{|c|c|c|c|c|c|c|}
\hline Collection medium & Motility (\%) & $\operatorname{VAP}(\mu \mathrm{m} / \mathrm{s})$ & $\mathbf{V S L}(\mu \mathrm{m} / \mathrm{s})$ & $\mathbf{V C L}(\mu \mathrm{m} / \mathrm{s})$ & $\mathbf{A L H}(\mu \mathrm{m})$ & LIN $(\%)$ \\
\hline Non-frozen group & $73 \pm 2^{a}$ & $119 \pm 4^{\mathrm{a}}$ & $84 \pm 1^{a}$ & $232 \pm 16^{a}$ & $14 \pm 1^{a}$ & $37 \pm 3^{a}$ \\
\hline $290 \mathrm{mmol} / \mathrm{kg}$ group & $28 \pm 4^{b}$ & $76 \pm 4^{b}$ & $48 \pm 3^{b}$ & $154 \pm 6^{b}$ & $9 \pm 1^{b}$ & $32 \pm 1^{\mathrm{a}}$ \\
\hline $415 \mathrm{mmol} / \mathrm{kg}$ group & $29 \pm 4^{b}$ & $90 \pm 2^{c}$ & $52 \pm 2^{b}$ & $179 \pm 2^{b}$ & $11 \pm 1^{b}$ & $31 \pm 1^{\mathrm{a}}$ \\
\hline
\end{tabular}

Different superscripts in a column indicate significant difference, $P<0.05 .{ }^{*}$ Sperm motion parameters were measured in $290 \mathrm{mmol} / \mathrm{kg}$ DPBS containing $2 \mathrm{mg} / \mathrm{ml} \mathrm{BSA}$ after thawing.

\section{Discussion}

The protocol for murine sperm cryopreservation developed by Nakagata (2000a, 2000b) has been widely used in different laboratories all over the world. The fertilizing ability of cryopreserved murine spermatozoa, however, is less than that of fresh spermatozoa in general and is especially low in many inbred strains (Sztein et al. 2000, Nishizono et al. 2004). Understanding the fundamental cryobiology of murine spermatozoa will assist in the development of improved freezing protocols for murine spermatozoa.

Studies have found that spermatozoa of many mammalian species are stored in a hyperosmotic environment in the epididymal fluid, and during the transit along the male genital tract (seminiferous tubules, epididymides, and vas deferens) spermatozoa are continuously exposed to high osmolality (Yeung et al. 1999, 2006, Cooper \& Yeung 2003). The osmolality of human testicular tubular fluid is $312-380 \mathrm{mmol} / \mathrm{kg}$ and the osmolality of human fresh seminal plasma is reported to be $380 \mathrm{mmol} / \mathrm{kg}$ (Polak \& Daunter 1984), and the osmolality of epididymal fluid of $\mathrm{C} 57 \mathrm{BL} / 6$ mouse is $415 \mathrm{mmol} / \mathrm{kg}$ (Yeung et al. 1999, 2000, Cooper \& Barfield 2006, Cooper et al. 2008), for example. Therefore, the examination of the effects of osmolalities of collection media on sperm fertility and the osmotic characteristics of murine spermatozoa collected in media with the osmolality of seminal fluid with a comparison of spermatozoa collected in isosmotic media will be useful to determine optimal media properties and cryopreservation protocols for murine spermatozoa.

\section{Experiment 1. The comparison of motion parameters of spermatozoa collected in 290 and $415 \mathrm{mmol} / \mathrm{kg}$ DPBS}

Our present study showed that the osmolality of the solution used for sperm collection and the genetic background of mice can affect the motion parameters of the spermatozoa. For the ICR strain, the motility of spermatozoa collected in isosmotic solution (290 $\mathrm{mmol} / \mathrm{kg}$ ) was slightly but significantly lower than that of spermatozoa collected in $415 \mathrm{mmol} / \mathrm{kg}$ solution, but for the $\mathrm{C} 57 \mathrm{BL} / 6$ strain, the motility of spermatozoa collected in isosmotic DPBS $(290 \mathrm{mmol} / \mathrm{kg})$ was significantly higher than that of spermatozoa collected in $415 \mathrm{mmol} / \mathrm{kg}$ DPBS. These results indicate that a hyperosmotic environment $(415 \mathrm{mmol} / \mathrm{kg}$ ) may depress sperm motility of C57BL/6 mice but not of ICR mice. In this study, most of the other sperm motion parameters including VAP, VSL, VCL, and LIN of motile spermatozoa collected in $290 \mathrm{mmol} / \mathrm{kg}$ DPBS were found to be significantly higher compared with those of spermatozoa collected in $415 \mathrm{mmol} / \mathrm{kg}$ solutions in both strains. These results suggest that the exposure of murine spermatozoa to isosmotic conditions $(290 \mathrm{mmol} / \mathrm{kg}$ ) may activate murine spermatozoa by increasing the velocity of motile spermatozoa. By contrast, the exposure of murine spermatozoa to osmotic conditions similar to epididymal fluid seems to keep spermatozoa quiescent by depressing the activation of spermatozoa. Studies have shown that human spermatozoa collected in a medium with the same osmolality as seminal plasma $(380 \mathrm{mmol} / \mathrm{kg})$ results in an influx of calcium from the extracellular solution upon exposure to isotonic medium $(300 \mathrm{mmol} / \mathrm{kg}$ ), and this osmotically sensitive calcium influx may have a crucial regulatory role in the cellular events of sperm activation and fertilization (Rossato et al. 1996). Therefore, the physiological role of maintaining spermatozoa at a hypertonic surrounding in males is believed to prevent capacitation before spermatozoa are ejaculated into the female genital tract (Fisch et al. 1990, Rossato et al. 1996).

\section{Experiment 2. The effect of anisosmotic treatments on sperm motion parameters (motility, VAP, VSL, VCL, $A L H$, and LIN)}

Murine spermatozoa are very sensitive to osmotic volume excursions (Willoughby et al. 1996, Songsasen \& Leibo 1997, Walters et al. 2005). For in vitrowork, spermatozoa are usually collected in solutions with an osmolality of

Table 3 Fertility of fresh spermatozoa (non-frozen group) and frozenthawed spermatozoa that were collected in 290 and $415 \mathrm{mmol} / \mathrm{kg}$ group media before cryopreservation and the development of embryos.

\begin{tabular}{lccc}
\hline & & \multicolumn{2}{c}{$\begin{array}{c}\text { Developmental stage } \\
\text { reached }(\%)\end{array}$} \\
\cline { 3 - 4 } $\begin{array}{l}\text { Spermatozoa } \\
\text { for IVF }\end{array}$ & $\begin{array}{c}\text { Total no. of } \\
\text { oocytes }\end{array}$ & 2-Cell & Blastocyst \\
\hline Non-frozen group & 72 & $48(66.7 \%)^{\mathrm{a}}$ & $30(62.5 \%)^{\mathrm{a}}$ \\
$290 \mathrm{mmol} / \mathrm{kg}$ group & 63 & $26(41.3 \%)^{\mathrm{b}}$ & $13(50.0 \%)^{\mathrm{b}}$ \\
$415 \mathrm{mmol} / \mathrm{kg}$ group & 70 & $49(70.0 \%)^{\mathrm{a}}$ & $35(71.4 \%)^{\mathrm{a}}$ \\
\hline
\end{tabular}

Different superscripts in a column indicate significant difference, $P<0.05$. 
$290 \mathrm{mmol} / \mathrm{kg}$. It has been demonstrated that the change of osmolality from $\sim 415 \mathrm{mmol} / \mathrm{kg}$ to $290 \mathrm{mmol} / \mathrm{kg}$ results in active cell volume regulation and defects in the regulatory mechanism will result in male infertility (Yeung et al. 1999, Cooper et al. 2008). This change may have some profound effects on spermatozoa's ability to tolerate subsequent osmotic challenge, such as the addition and removal of CPAs during cryopreservation. In addition, much of the loss of sperm fertilizing ability during cryopreservation is associated with osmotic injury (Meyers 2005). Sperm motion parameters such as motility, VAP, VSL, VCL, ALH, and LIN have been found to be highly related to IVF rate and are useful in fertility prediction (Toth et al. 1991, Verstegen et al. 2002), In this study, spermatozoa from ICR and C57BL/6 mice were collected in (1) $290 \mathrm{mmol} / \mathrm{kg}$ DPBS, which is considered as the nominal isosmolality in many studies (Willoughby et al. 1996, Songsasen \& Leibo 1997, Agca et al. 2002, Walters et al. 2005) and (2) $415 \mathrm{mmol} / \mathrm{kg}$ DPBS, which has been shown to be the physiological osmolality of epididymal fluid of C57BL/6 mouse (Yeung et al. 1999, 2000). When spermatozoa were collected in $290 \mathrm{mmol} /$ kg DPBS, we found that both hyposmotic and hyperosmotic treatments resulted in sperm motility loss in both strains, and a return to $290 \mathrm{mmol} / \mathrm{kg}$ did not result in significant recovery in sperm motility. Similar to the response of sperm motility, the anisosmotic treatments also resulted in a decrease of VAP, VSL, VCL, ALH, and LIN of motile spermatozoa collected in $290 \mathrm{mmol} / \mathrm{kg}$ DPBS in both mouse strains. However, unlike motility, certain motion parameters could be recovered after return to $290 \mathrm{mmol} / \mathrm{kg}$. When murine spermatozoa were collected in DPBS with the osmolality $(415 \mathrm{mmol} / \mathrm{kg})$ of epididymal fluid, however, the responses of spermatozoa to the anisosmotic treatments were clearly different compared with the spermatozoa collected in isosmotic DPBS $(290 \mathrm{mmol} / \mathrm{kg}$ ). In this study, the responses of motion parameters (VAP, VSL, VCL, ALH, and LIN) of spermatozoa collected in $415 \mathrm{mmol} / \mathrm{kg}$ DPBS were similar between the two mouse strains: the exposure of spermatozoa to hyposmotic $(225 \mathrm{mmol} / \mathrm{kg})$ and isosmotic solution $(290 \mathrm{mmol} / \mathrm{kg})$ resulted in an increase of the motion parameter values of motile spermatozoa in general. After a return to $415 \mathrm{mmol} / \mathrm{kg}$, the motion parameter values significantly dropped to the same level or below of those spermatozoa kept in $415 \mathrm{mmol} / \mathrm{kg}$ solutions. These results are consistent with the theory that the exposure of murine spermatozoa to an osmotic condition similar to the epididymal fluid keeps spermatozoa quiescent by depressing the motility and velocity of spermatozoa, but that the exposure of murine spermatozoa to an isosmotic condition $(290 \mathrm{mmol} / \mathrm{kg}$ ) or hyposmotic condition $(225 \mathrm{mmol} / \mathrm{kg}$ ) could activate murine spermatozoa. The responses of spermatozoa to hyperosmotic exposure were different between ICR and C57BL/ 6 . In the ICR mouse, we found that the motility of spermatozoa collected in $415 \mathrm{mmol} / \mathrm{kg}$ DPBS maintained
$41.4 \pm 3.9 \%$ of their original motility after exposure to $600 \mathrm{mmol} / \mathrm{kg}$ solution and upon return to $415 \mathrm{mmol} / \mathrm{kg}$ conditions, while the motility of spermatozoa collected in $290 \mathrm{mmol} / \mathrm{kg}$ DPBS decreased to $13.4 \pm 2.4 \%$ after exposure to $600 \mathrm{mmol} / \mathrm{kg}$ solution and being returned to isotonic condition. These results indicate that the collection of spermatozoa in $415 \mathrm{mmol} / \mathrm{kg}$ DPBS could improve the maintenance of sperm motility upon exposure to hypertonic treatments $(600 \mathrm{mmol} / \mathrm{kg})$ in the ICR mouse. However, similar results were not observed in spermatozoa from C57BL/6 mice. The effect of the osmolality of spermatozoa collecting medium seems to be related to the genetic background of mouse. The failure to extend the resistance to hyperosmotic stress in C57BL/6 spermatozoa by collecting them in $415 \mathrm{mmol} / \mathrm{kg}$ solutions may be a reason why sperm cryopreservation of inbred mice, especially the $\mathrm{C} 57 \mathrm{BL} / 6$ strain, is not as successful as it is in hybrid or outbreed strains.

In this study, despite of the increase of other motion parameters such as VAP, VSL, VCL, and LIN, the exposure of ICR mouse spermatozoa collected in $415 \mathrm{mmol} / \mathrm{kg}$ DPBS to $290 \mathrm{mmol} / \mathrm{kg}$ DPBS did not increase sperm motility, a phenomenon observed in C57BL/6 mouse. This may be in part due to the fact that the osmolality of epididymal fluid used here was from measurements on C57BL/6 strain (Yeung et al. 1999, 2000). Because we see differences in other membrane parameters and sensitivities (Willoughby et al. 1996), it is reasonable to expect that the osmolality of epididymal fluid could be different for different mouse genetic backgrounds. Measurements of these osmolalities would be illustrative. Recent studies have shown that the physical osmolalities of mouse cauda epididymides ranges from 375 to $500 \mathrm{mmol} / \mathrm{kg}$ depending on strains or lines (Cooper \& Barfield 2006, Cooper et al. 2008). We suspect that the different response of sperm motility between ICR and C57BL/ 6 mouse may be caused by a higher physiological osmolality of epididymal fluid in the ICR strain. Therefore, when ICR mouse spermatozoa are exposed to $415 \mathrm{mmol} /$ $\mathrm{kg}$ medium they are still hyposmotically challenged and the depression to the velocity of spermatozoa is less marked compared with spermatozoa from C57BL/6 strain, and a high percentage of spermatozoa are still evaluated as motile using the Hamilton Thorne.

It has been shown that the freezing/thawing processes can result in an acceleration of sperm capacitation (Critser et al. 1987, Watson 1995) and spermatozoa in this state display hyperactivated motion parameters - a reduction in progressive motility and LIN, with a concomitant increase in beat cross frequency (BCF) and ALH (Ohmuro \& Ishijima 2006, Muiño et al. 2008). However, it seems that osmotic stress may not be a contributing factor to this phenomenon because there was not a significant decrease in ALH and significant increase in BCF (data not shown) in both strains. 


\section{Experiment 3. An investigation of the effects of collection media osmolality on sperm fertility after cryopreservation}

Since the OTLs of murine spermatozoa collected in 290 and $415 \mathrm{mmol} / \mathrm{kg}$ medium are different, we examined the effect of osmolalities of collection media on sperm fertility after cryopreservation. When we collected ICR mouse spermatozoa into 290 and $415 \mathrm{mmol} / \mathrm{kg}$ DPBS medium and further diluted with cryopreservation medium, however, the post-thaw sperm motility was 15 and $3 \%$ respectively. These results made us consider that the extremely low cryosurvival might be due to the toxic effect of sodium chloride during sperm freezing and thawing. Therefore, we used raffinose instead of sodium chloride to prepare the 290 and $415 \mathrm{mmol} / \mathrm{kg}$ medium to collect spermatozoa and performed the consequent sperm cryopreservation. In our study, after collection in $100 \mu \mathrm{l} 290$ or $415 \mathrm{mmol} / \mathrm{kg}$ medium, spermatozoa were further diluted at a ratio of 1-9 with regular murine sperm cryopreservation medium for cryopreservation. Note that the difference in raffinose concentration between the two groups was negligible. Post-thaw motility after collection in raffinose containing media at 290 and $415 \mathrm{mmol} / \mathrm{kg}$ was 30 and $28 \%$ respectively for ICR mice and 28 and $29 \%$ respectively for the $\mathrm{C} 57 \mathrm{BL} / 6$ mice. We did not examine the differences in kinematics of spermatozoa after freezing-thawing between the two strains because cryopreservation was done without penetrating CPA and no hypotonic volume change would be expected. Instead, we performed IVF using frozen/thawed spermatozoa from ICR. In addition to the increased ability to resist hyperosmotic challenge based on the OTL experiment, spermatozoa collected in $415 \mathrm{mmol} / \mathrm{kg}$ medium also had higher fertility and developmental competence than those collected in $290 \mathrm{mmol} / \mathrm{kg}$ medium, as demonstrated by the cleavage and blastocyst rates. The increased fertility and developmental competence of spermatozoa collected in $415 \mathrm{mmol} / \mathrm{kg}$ may be partially due to the reduced chance of cell swelling during cryopreservation. For spermatozoa collected in $290 \mathrm{mmol} / \mathrm{kg}$ medium, the direct exposure from epididymides (hyperosmotic) to isosmotic condition subjected them to cell swelling, and volume regulation driven by this osmotic change might initiate sperm capacitation and activation (Rossato et al. 1996). However, after further dilution with hyperosmotic sperm cryopreservation medium and subsequent extracellular ice formation during freezing spermatozoa were subjected to cell shrinkage. After thawing spermatozoa experienced swelling during the removal of CPAs and the process of IVF. By contrast, spermatozoa collected in $415 \mathrm{mmol} / \mathrm{kg}$ medium experienced cell swelling only after cryopreservation and thawing. Since sperm swelling leads to the loss of osmolytes and the ability of spermatozoa to regulate volume, both of which are related to sperm capacitation and fertility (Rossato et al. 1996, Cooper \& Barfield 2006), and dysfunction of the volume regulatory ability of spermatozoa to hyposmotic condition causes infertility (Yeung et al. 2006, Cooper \& Barfield 2006, Cooper et al. 2008), the extra experience of osmotic challenges and the associated cell swelling of the group of spermatozoa collected in $290 \mathrm{mmol} / \mathrm{kg}$ medium might lead to reduced responses to the hyposmotic challenges when spermatozoa from this group are subjected to IVF and result in lower fertility. However, more studies are needed in this direction.

In conclusion, the osmolalities of sperm collecting solutions affected the OTLs of spermatozoa. Spermatozoa collected in a hyperosmotic solution with an osmolality similar to epididymal fluid $(415 \mathrm{mmol} / \mathrm{kg}$ ) resulted in an increase in sperm osmotic tolerance to higher osmolality compared with those collected in $290 \mathrm{mmol} / \mathrm{kg}$ and also resulted in high fertility of spermatozoa after cryopreservation. These results are useful when designing protocols that prevent or reduce osmotic damage and loss of fertility during handling and cryopreservation.

\section{Materials and Methods}

\section{Animals}

Mature male mice between 10 and 12 weeks old from ICR and C57BL/6 genetic backgrounds (Harlan, Indianapolis, IN, USA) were used as sperm donors, and female ICR mice between 4 and 5 weeks old were used as oocyte donors for IVF in this study. The mice were housed in a room with a $12 \mathrm{~h}$ light: $12 \mathrm{~h}$ darkness cycle and provided with sterile food and water ad libitum. The temperature was controlled at $22{ }^{\circ} \mathrm{C}$. All animals were handled in accordance with the policies of the University of Missouri Animal Care and Use Committee, and the Guide for the Care and Use of Laboratory Animals of Association for Assessment and Accreditation of Laboratory Animal Care International.

\section{Media}

All chemicals were from Sigma Chemical unless otherwise stated. In experiment 1, DPBS, (Gibco \#14287-080; Invitrogen) was used to prepare solutions with different osmolalities. Hyposmotic solutions (75, 150, and $225 \mathrm{mmol} / \mathrm{kg}$ ) were prepared by diluting the isosmotic DPBS medium (290 mmol/kg) with water, and hyperosmotic solutions (415, 600,1200 , and $2400 \mathrm{mmol} / \mathrm{kg}$ ) were prepared by adding appropriate amounts of sodium chloride to isotonic DPBS medium. Osmolalities of the solutions were measured using a vapor pressure osmometer (VAPRO 5520, Wescor, Logan, UT, USA) with an accuracy of $\pm 5 \mathrm{mmol} / \mathrm{kg}$. Prior to use, $2 \mathrm{mg} / \mathrm{ml}$ BSA was supplemented into all of the solutions.

In experiment 2, murine sperm cryopreservation medium containing $18 \%$ raffinose and 3\% skimmed milk was prepared as described by Nakagata (2000a, 2000b). Media at osmolalities of 290 and $415 \mathrm{mmol} / \mathrm{kg}$ prepared by dissolving 
appropriate amounts of raffinose in water containing $3 \%$ skimmed milk were used as sperm collection media before cryopreservation in experiment 2 .

\section{Sperm motion parameters analysis}

Computer-assisted sperm analysis (CASA; Hamilton Thorne IVOS v 12.2c, Beverly, MA, USA) was used to analyze murine sperm motion parameters: sperm motility $(\%), \operatorname{VAP}(\mu \mathrm{m} / \mathrm{s}), \mathrm{VSL}$ $(\mu \mathrm{m} / \mathrm{s}), \mathrm{VCL}(\mu \mathrm{m} / \mathrm{s}), \mathrm{ALH}(\mu \mathrm{m})$, and LIN $(\%)$. Spermatozoa were analyzed according to the following parameters described by Hamilton Thorne: frames acquired 30, frame rate $60 \mathrm{~Hz}$, minimum contrast 50, minimum cell size 5 pixels, default cell size 8 pixels, default cell intensity 90, VAP cut off $5 \mu \mathrm{m} / \mathrm{s}$, intensity gate $0.50-1.30$, size gate $0.30-1.95$, elongation gate $0-87$, magnification 0.79 , video frequency 60 , temperature set $37^{\circ} \mathrm{C}$, and chamber depth $80 \mu \mathrm{m}$.

\section{Experiment 1. Determination of the OTLS of ICR and C57BL/6 spermatozoa collected in 290 and $415 \mathrm{mmol} / \mathrm{kg}$ DPBS}

Spermatozoa from ICR mice $(n=8)$ and C57BL/6 mice $(n=6)$ were used for the experiment, and all of the experiments were performed at room temperature. Mice were killed and the cauda epididymidum were excised using eye scissors. Blood and adipose tissue were removed. One cauda epididymis of each mouse was placed into $500 \mu$ l DPBS (290 mmol/kg), and the contralateral cauda epididymis was placed into $500 \mu \mathrm{l}$ DPBS (415 mmol/kg). Cauda epididymidum were well minced, and murine spermatozoa were allowed to swim out for $10 \mathrm{~min}$ at $37^{\circ} \mathrm{C}$ in each solution. Sperm suspensions $(\sim 2 \times$ $10^{7} \mathrm{cells} / \mathrm{ml}$ ) in $20 \mu \mathrm{l}$ aliquots collected in $290 \mathrm{mmol} / \mathrm{kg}$ DPBS were added to each of seven $1.5 \mathrm{ml}$ Eppendorf centrifuge tubes containing DPBS solutions with different osmolalities (75, 150, 225, 290, 415, 600, and $1200 \mathrm{mmol} / \mathrm{kg}$ ) respectively. Spermatozoa were equilibrated in these DPBS solutions with different osmolalities for $5 \mathrm{~min}$, and the sperm motion parameters of each treatment were evaluated immediately using the Hamilton Thorne IVOS CASA system. The anisosmotically treated spermatozoa, which were collected in $290 \mathrm{mmol} / \mathrm{kg}$ DPBS solution, were then returned to osmolality (290 mmol/kg) by adding appropriate amounts of DPBS solutions at other corresponding osmolalities without centrifugation (Willoughby et al. 1996, Walters et al. 2005). The treatments of sperm suspension collected in $415 \mathrm{mmol} / \mathrm{kg}$ DPBS solution were essentially the same as those collected in $290 \mathrm{mmol} / \mathrm{kg}$ DPBS except that the anisosmotically treated spermatozoa were returned to $415 \mathrm{mmol} / \mathrm{kg}$ rather than $290 \mathrm{mmol} / \mathrm{kg}$. The CASA evaluation for spermatozoa collected in $415 \mathrm{mmol} / \mathrm{kg}$ DPBS also followed the procedure of spermatozoa collected in $290 \mathrm{mmol} / \mathrm{kg}$ DPBS.

\section{Experiment 2. Sperm cryopreservation and IVF}

Sperm cryopreservation

Spermatozoa from ICR mice $(n=6)$ and C57BL/6 mice $(n=4)$ were used for the experiment. Sperm collection was performed as described in Experiment 1 except that cauda epididymidum of each mouse was collected in $100 \mu \mathrm{l}$ medium prepared by dissolving different amounts of raffinose in water containing $3 \%$ skimmed milk with osmolalities of 290 and $415 \mathrm{mmol} / \mathrm{kg}$ respectively rather than DPBS. Spermatozoa were allowed to swim out of the cauda epididymides at $37^{\circ} \mathrm{C}$ for $10 \mathrm{~min}$ and were further diluted with $1 \mathrm{ml}$ sperm cryopreservation medium prepared by dissolving $18 \%$ raffinose and $3 \%$ skimmed milk in water (Nakagata 2000b). Diluted sperm suspensions (100 $\mu$ l each) were loaded in $0.25 \mathrm{ml}$ cryostraws (Conception Technologies, San Diego, CA, USA) and frozen in liquid nitrogen vapor according to the method described by Nakagata (2000b). Straws were thawed by directly transferring from the liquid nitrogen into a $37^{\circ} \mathrm{C}$ water bath. Frozen-thawed sperm suspensions were diluted with $1 \mathrm{ml}$ DPBS medium supplemented with $2 \mathrm{mg} / \mathrm{ml} \mathrm{BSA}$ and centrifuged at $300 \mathrm{~g}$ for $5 \mathrm{~min}$. The soft pellets were resuspended in DPBS medium with $2 \mathrm{mg} / \mathrm{ml}$ BSA and an aliquot was taken for sperm motion parameter examination.

IVF

Since the fertilization rate of $\mathrm{C} 57 \mathrm{BL} / 6$ strain is typically low when cryopreserved spermatozoa are used to inseminate oocytes using a standard murine IVF protocol (Sztein et al. 2000), IVF was only used for assessing the fertility of cryopreserved spermatozoa from ICR mice collected in media with osmolalities of 290 and $415 \mathrm{mmol} / \mathrm{kg}$ (four replicates).

Three 4 to 5 week-old ICR female mice were superovulated by i.p. injection of $5 \mathrm{IU}$ pregnant mare serum gonadotropin followed by $5 \mathrm{IU}$ human chorionic gonadotropin (hCG) for each replicate experiment. Thirteen hours after the hCG injection, the females were killed and the oviducts were removed. The oocyte-cumulus complexes (COCs) were isolated in flushing holding medium (Lawitts \& Biggers 1993) containing $0.4 \%$ BSA. Cumulus cells were removed by treating the COCs with $1 \mathrm{mg} / \mathrm{ml}$ hyaluronidase.

Fresh or washed frozen/thawed spermatozoa were added to $100 \mu \mathrm{l}$ human tubal fluid (Quinn et al. 1985) medium with $4 \mathrm{mg} / \mathrm{ml} \mathrm{BSA}$ at the concentration of $1 \times 10^{6}$ motile spermatozoa $/ \mathrm{ml}$ and were cultured at $37^{\circ} \mathrm{C}$ under $5 \% \mathrm{CO}_{2}$ in air for $1 \mathrm{~h}$ respectively. Oocytes were randomly divided into three groups and inseminated with fresh or frozen/thawed spermatozoa that were collected in 290 or $415 \mathrm{mmol} / \mathrm{kg}$ raffinose medium before cryopreservation respectively. After $6 \mathrm{~h}$ of co-culture with spermatozoa, the oocytes of each group were washed to eliminate excess spermatozoa and then cultured in $30 \mu \mathrm{l}$ drops of potassium simplex optimization medium (KSOM, Lawitts \& Biggers 1993) with $1 \mathrm{mg} / \mathrm{ml}$ BSA. The next morning, the number of two-cell embryos was scored, and the embryos were transferred to fresh drops of KSOM medium with $1 \mathrm{mg} / \mathrm{ml} \mathrm{BSA}$ for culture until the blastocyst stage.

\section{Statistical analysis}

All data are expressed as mean \pm S.E.M. A paired two-tail $t$-test was used to analyze the difference between sperm motion parameters of spermatozoa collected in 290 and $415 \mathrm{mmol} / \mathrm{kg}$ 
DPBS in Experiment 1. ANOVA using the General Linear Model univariate procedure of the SPSS software (SPSS INC., Chicago, IL, USA) and a Tukey multiple comparison test was used to determine the effects of osmolalities (290 and $415 \mathrm{mmol} / \mathrm{kg}$ ) of sperm collecting media and genetic backgrounds on sperm motion parameters in experiment 1. An ANOVA followed by Tukey's test was used to analyze the differences of sperm motion parameters, the fertilization rate and a Dunnet's post hoc test was used to compare embryo development among fresh sperm controls and cryopreserved spermatozoa collected in 290 and $415 \mathrm{mmol} / \mathrm{kg}$ media in experiment 2. Differences were considered significant using an $\alpha$ value of 0.05 .

\section{Declaration of interest}

The authors declare that there is no conflict of interest that would prejudice the impartiality of this scientific work.

\section{Funding}

This research was funded by grants from the National Center for Research Resources, National Institutes of Health $3 \cup 42$ RR014821, 7 R24 RR193194.

\section{References}

Agca Y, Gilmore J, Byers M, Woods EJ, Liu J \& Critser JK 2002 Osmotic characteristics of mouse spermatozoa in the presence of extenders and sugars. Biology of Reproduction 67 1493-1501.

Bath ML 2003 Simple and efficient in vitro fertilization with cryopreserved c57bl/6j mouse sperm. Biology of Reproduction 68 19-23.

Cooper TG \& Barfield JP 2006 Utility of infertile male models for contraception and conservation. Molecular and Cellular Endocrinology $250206-211$.

Cooper TG \& Yeung CH 2003 Acquisition of volume regulatory response of sperm upon maturation in the epididymidis and the role of the cytoplasmic droplet. Microscopy Research and Technique 61 28-38.

Cooper TG, Barfield JP \& Yeung CH 2008 The tonicity of murine epididymal spermatozoa and their permeability towards common cryoprotectants and epididymal osmolytes. Reproduction 135 625-633.

Critser JK \& Mobraaten LE 2000 Cryopreservation of murine spermatozoa. ILAR Journal 41 197-206.

Critser JK, Arneson BW, Aaker DV, Huse-Benda AR \& Ball GD 1987 Cryopreservation of human spermatozoa. II. Post thaw chronology of motility and of zona-free hamster ova penetration. Fertility and Sterility 35 253-257.

Fisch B, Goldberg I, Ovadia J \& Tadir Y 1990 Physicochemical properties of follicular fluid and their relation to in vitro fertilization (IVF) outcome. Journal of In Vitro Fertilization and Embryo Transfer 7 67-73.

Katkov II, Katkova N, Critser JK \& Mazur P 1998 Mouse spermatozoa in high concentrations of glycerol: chemical toxicity vs osmotic shock at normal and reduced oxygen concentrations. Cryobiology 37 325-338.

Knight J \& Abbott A 2002 Full house. Nature 417 785-786.

Koshimoto C \& Mazur P 2002 The effect of the osmolality of sugarcontaining media, the type of sugar, and the mass and molar concentration of sugar on the survival of frozen-thawed mouse sperm. Cryobiology 45 80-90.

Lawitts JA \& Biggers JD 1993 Culture of preimplantation embryos. Methods in Enzymology 225 153-164.

Meyers SA 2005 Spermatozoal response to osmotic stress. Animal Reproduction Science 89 57-64.

Muiño R, Rivera MM, Rigau T, Rodriguez-Gil JE \& Peña Al 2008 Effect of different thawing rates on post-thaw sperm viability, kinematic parameters and motile sperm subpopulations structure of bull semen. Animal Reproduction Science 109 50-64.

Nagy A 2003 Manipulating the Mouse Embryo: A Laboratory Manual, p 764 .
Nakagata N 2000a Cryopreservation of mouse spermatozoa. Mammalian Genome 11 572-576.

Nakagata N 2000b Mouse spermatozoa cryopreservation. Journal of Mammalian Ova Research 17 1-8.

Nakagata N, Okamoto M, Ueda O \& Suzuki H 1997 Positive effect of partial zona-pellucida dissection on the in vitro fertilizing capacity of cryopreserved c57bl/6j transgenic mouse spermatozoa of low motility. Biology of Reproduction 57 1050-1055.

Nishizono H, Shioda M, Takeo T, Irie T \& Nakagata N 2004 Decrease of fertilizing ability of mouse spermatozoa after freezing and thawing is related to cellular injury. Biology of Reproduction 71 973-978.

Ohmuro J \& Ishijima S 2006 Hyperactivation is the mode conversion from constant-curvature beating to constant-frequency beating under a constant rate of microtubule sliding. Molecular Reproduction and Development 73 1412-1421.

Polak B \& Daunter B 1984 Osmolarity of human seminal plasma. Andrologia 16 224-227.

Quinn P, Kerin JF \& Warnes GM 1985 Improved pregnancy rate in human in vitro fertilization with the use of a medium based on the composition of human tubal fluid. Fertility and Sterility 44 493-498.

Rossato M, Di Virgilio F \& Foresta C 1996 Involvement of osmo-sensitive calcium influx in human sperm activation. Molecular Human Reproduction 2 903-909.

Sharp J \& Mobraaten L 1997 To save or not to save: the role of repositories in a period of rapidly expanding development of genetically engineered strains of mice. In Transgenic Animals: Generation and Use, pp 525-532. Ed. LM Houdebine. Netherlands: Harwood Academic.

Songsasen N \& Leibo SP 1997 Cryopreservation of mouse spermatozoa. II. Relationship between survival after cryopreservation and osmotic tolerance of spermatozoa from three strains of mice. Cryobiology 35 255-269.

Stacy R, Eroglu A, Fowler A, Biggers J \& Toner M 2006 Thermal characterization of nakagata's mouse sperm freezing protocol. Cryobiology 52 99-107.

Sztein JM, Farley JS \& Mobraaten LE 2000 In vitro fertilization with cryopreserved inbred mouse sperm. Biology of Reproduction 63 1774-1780.

Toth GP, Stober JA, Zenick H, Read EJ, Christ SA \& Smith MK 1991 Correlation of sperm motion parameters with fertility in rats treated subchronically with epichlorohydrin. Journal of Andrology 12 54-61.

Verstegen J, Iguer-Ouada M \& Onclin K 2002 Computer assisted semen analyzers in andrology research and veterinary practice. Theriogenology 57 149-179.

Walters EM, Men H, Agca Y, Mullen SF, Critser ES \& Critser JK 2005 Osmotic tolerance of mouse spermatozoa from various genetic backgrounds: acrosome integrity, membrane integrity, and maintenance of motility. Cryobiology 50 193-205.

Watson PF 1995 Recent developments and concepts in the cryopreservation of spermatozoa and the assessment of their post-thawing function. Reproduction, Fertility, and Development 7 871-891.

Willoughby CE, Mazur P, Peter AT \& Critser JK 1996 Osmotic tolerance limits and properties of murine spermatozoa. Biology of Reproduction $\mathbf{5 5}$ 715-727.

Yeung CH, Sonnenberg-Riethmacher E \& Cooper TG 1999 Infertile spermatozoa of c-ros tyrosine kinase receptor knockout mice show flagellar angulation and maturational defects in cell volume regulatory mechanisms. Biology of Reproduction 61 1062-1069.

Yeung CH, Wagenfeld A, Nieschlag E \& Cooper TG 2000 The cause of infertility of male c-ros tyrosine kinase receptor knockout mice. Biology of Reproduction 63 612-618.

Yeung CH, Barfield JP \& Cooper TG 2006 Physiological volume regulation by spermatozoa. Molecular and Cellular Endocrinology 250 98-105.

Received 29 May 2008

First decision 2 July 2008

Revised manuscript received 12 November 2008

Accepted 21 November 2008 